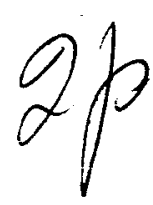

Reprinted from

The Phrsics of Fluns

Volume 7, Number 4, April 1964

\section{Shock-Tube Thermal Conductivity}

\author{
M. R. LAUver \\ Lewis Research Center, National Aeronautics and \\ Space Administration, Cleveland, Ohio \\ (Received 24 October 1962; revised manuscript received \\ 24 October 1963)
}

A SHOCK wave passing through a gas and reflecting from a wall at a right angle to its path suddenly exposes the wall to a hot quiescent body of gas. The initial temperature rise of the wall surface is a function of temperature $T$, thermal conductivity $k$, density, and heat capacities of the gas and the solid. Smiley ${ }^{1}$ combined equations of one-dimensional heat flow by conduction at constant pressure and the equation of continuity to analyze experimental data obtained with shock-heated argon at a Pyrex end wall. He reported $k$ 's for argon from $1000^{\circ}$ to $3000^{\circ} \mathrm{K}$. Hansen ${ }^{2}$ used an analysis based on one-dimensional heat flow by conduction combined with consideration of chemical reactions to interpret data obtained in a similar experiment with air. The results were reported as integrals of $k$. Thomson ${ }^{3}$ worked the equation of continuity into Hansen's analyses to include consideration of the heat transported by the movement of gas toward the cool wall. He used estimated values of $k$ to calculate the initial temperature rise of the wall surface for various shocked gas temperatures. The experimental data for air agreed somewhat better with his analysis.

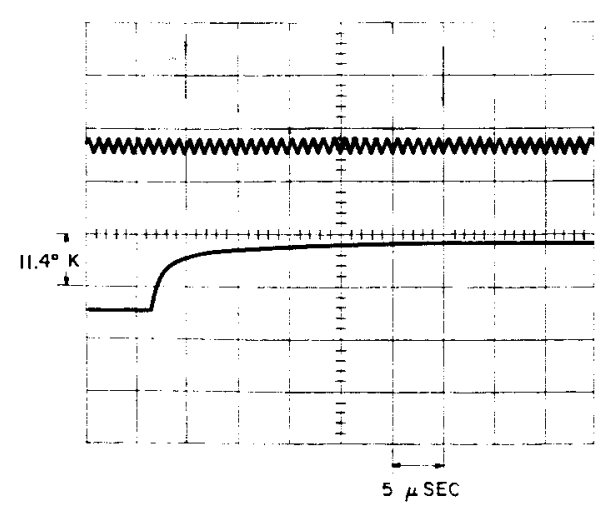

FIG. 1. Thin-film thermometer response in argon at $M_{\mathrm{s}}=3.74$ and $p_{1}=50$ Torr.

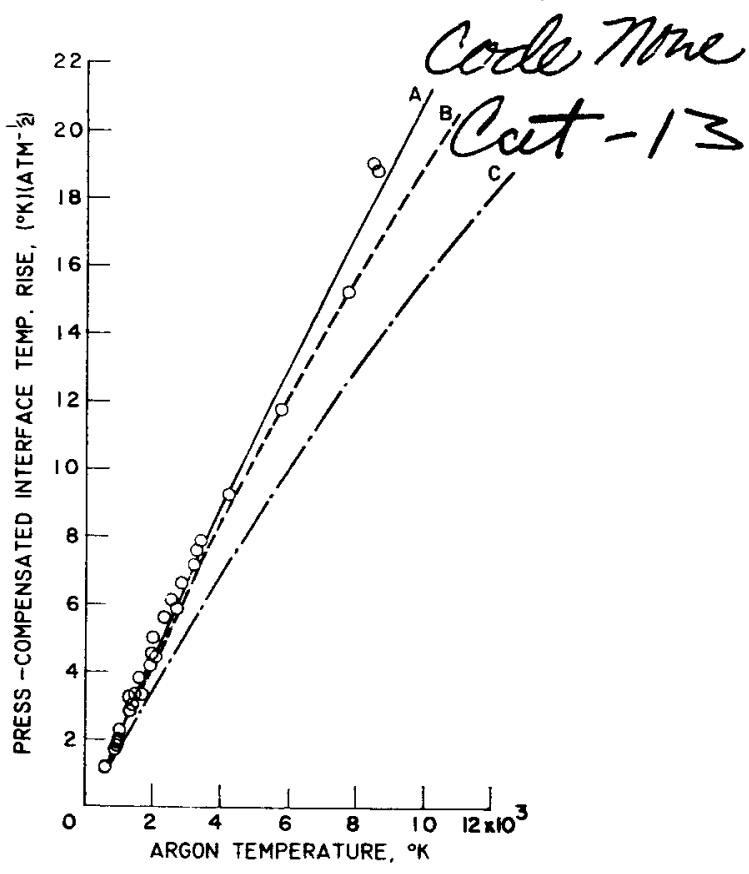

Fig. 2. Pyrex surface temperature rise in shock-heated argon. $O$, experimental data; curve a, Smiley and Thomson analyses, Amdur $k$; curve $\mathrm{b}$, Smiley and Thomson analyses, Hilsenrath $k$; curve c, Hansen analysis, Amdur $k$.

This note is a result of a recent experimental shock-tube study of thermal conductivities of gases. A thin-film platinum-on-Pyrex resistance thermometer was mounted normal to the shock travel in the center of a shock tube of 3 - by 3 -in. cross section. The distance from the diaphragm to the thermometer was $18 \mathrm{ft} 9 \mathrm{in}$. Based on shock speed, reflected shock temperatures of $665^{\circ}$ to $8580^{\circ} \mathrm{K}$ were obtained in argon by using a helium driver. A typical thermometer output record is shown in Fig. 1 .

The calculation of the $k$ of argon from the data by the method of Smiley was unsatisfactory because of the uncertainty of the results at temperatures higher than about $3000^{\circ} \mathrm{K}$.

As another approach, values of $k$ were assumed ${ }^{4}$ and the relation between the surface temperature rise and hot gas temperatures was calculated by the methods of Smiley, Hansen, and Thomson. The results are compared with experimental data in Fig. 2. The Smiley and Thomson analyses 
give the same results, and these agree with the experimental data better than the Hansen predictions. The Smiley and Thomson analyses were also made with $k=0.379 \times 10^{-5} T^{\mathbf{z}} /(167+T)$, (cal) $\left(\mathrm{cm}^{-1}\right)\left(\mathrm{sec}^{-1}\right)\left({ }^{\circ} \mathrm{K}^{-1}\right)$,- which gives values of $k$ that are about the same as those of Amdur to $1000^{\circ} \mathrm{K}$, but $24 \%$ lower at $5000^{\circ} \mathrm{K}$, and $36 \%$ lower at $10000^{\circ} \mathrm{K}$. As shown in Fig. 2, the predicted temperature rise is decreased by only about $2 \%$ at $5000^{\circ} \mathrm{K}$ and $5 \%$ at $10000^{\circ} \mathrm{K}$. In other words, an error of $0.2^{\circ} \mathrm{K}$ in the temperature rise (at $1 \mathrm{~atm}$ ) or of $100^{\circ} \mathrm{K}$ in the reflected shock temperature at $5000^{\circ}$ is equivalent to a change in $k$ of about $20 \%$.

In conclusion, the experimental data are in general agreement with those predicted by analyses developed by Smiley and Thomson. The data thus far obtained do not have the precision necessary to distinguish between theoretical $k$ 's that differ by only a few percent. They do indicate that, to about $8600 . \mathrm{K}$, the generally accepted values for argon are approximately correct.

The author is indebted to John L. Gregg for helpful consultations and for the programming.

1 E. F. Smiley, Ph.D. Thesis, The Catholic University of America, 1957.

'C. F. Hansen, R. A. Early, F. E. Alzofon, and F. C. Witteborn, NASA TR R-27 (1959).

${ }^{3}$ T. A. Thomson, Australian Defence Scientific Service, Aero. Res. Labs., Aerodynamics Note 186 (1960).

4 I. Amdur, and E. A. Mason, Phys. Fluids 1, 370 (1958).

$5 \mathrm{~J}$. Hilsenrath and Y. S. Touloukian, Trans. ASME 76, 967 (1954). 